\title{
A numerical-experimental approach to assess emission performance of new generation engines during the cold transient
}

\section{Paolo Iodice* and Adolfo Senatore}

\author{
Dipartimento di Ingegneria Industriale, Università degli Studi di Napoli Federico II, \\ Via Claudio 21 - 80125 Napoli, Italy \\ *E-mail: paolo.iodice@unina.it
}

Phone: (+39) 081 7683277; Fax: (+39) 0812396097

\begin{abstract}
Modern vehicles equipped with a spark ignition engine come with fuel injection and electronic mixture control, in combination with a three-way catalyst: as a result, carbon monoxide and unburned hydrocarbon cold emissions represent a significant share of total emissions if compared with those given off in hot conditions, so implying direct consequences on the air quality of metropolitan areas. The purpose of this research is to investigate the engine efficiency and emissive performance of last generation engines during the cold-start phase. For this aim, an experimental-analytical procedure was optimised and applied to study the cold emission behaviour of two motorcycles, characterised by similar technical specifications; the exhaust emissions of these motorcycles were measured on a chassis dynamometer in the laboratories of the National Research Council (CNR-Italy). By using this calculation procedure and the emission results measured during the experimental tests, the duration of the cold phase and the total emissions released during the cold-start transient were evaluated for carbon monoxide and unburned hydrocarbons. The average values of cold emission factors and warm-up transient durations obtained for unburned hydrocarbons were $1.05 \mathrm{~g} / \mathrm{km}$ and $162 \mathrm{~s}$, respectively. Regarding carbon monoxide, the average values of cold emission factors and warm-up transient durations were $14.9 \mathrm{~g} / \mathrm{km}$ and $152 \mathrm{~s}$, respectively. The results of this study are very useful for better characterising the emission levels of the last generation motorcycles under real urban conditions.
\end{abstract}

Keywords: SI engine performance; cold-start phase; emission model; motorcycle emission factors; chassis dynamometer.

\section{INTRODUCTION}

Nowadays, a large proportion of the total road transport emissions of carbon monoxide and unburned hydrocarbons, especially in urban areas, is caused by vehicles being driving under cold-start conditions, despite them having electronic mixture control and a catalytic converter. Besides, in the last years two-wheelers vehicles are increasingly being used and represent a large proportion of motorised vehicles, especially in urban areas of Asia and Europe [1,2]. Starting from these considerations, a numerical-analytical analysis was performed on the cold exhaust emissions of two high-performance motorcycles (1000 $\mathrm{cm}^{3}$ and Euro-3 legislative category). In recent years, advances in internal combustion engines, such as the common rail, the adoption of improved lubricants, the development of control electronics and the use of catalytic converters, have allowed the considerable reduction of both fuel consumption and pollutant emissions during the steady state 
performance of internal combustion engines [3-5]. However, the cold-start performance of vehicle engines remains a crucial phase because the thermal efficiency of the last generation engines is meaningfully lower at cold-start than when the vehicles reach steady-state temperatures owing to sub-optimal component and lubricant temperatures [6-8]. Consequently, whilst the vehicle may have acceptable performance credentials once fully warm, poor cold-start performance may possibly result in the vehicle failing key emission tests and being assigned a high fuel consumption. It is therefore critical to make attempts to improve fuel consumption and emissive behaviour during the cold-start and warm-up phases, particularly as consumer driving habits often involve trips that are of a sufficiently short distance that the engine never reaches its optimum operating temperature [3]. In this regard, Goettler, Vidger [9] estimated that up to $80 \%$ of trips made in the United States of America are less than $15 \mathrm{~km}$ in length whilst Jarrier, Champoussin [10] claimed the mean European car journey to be approximately $10 \mathrm{~km}$. Andrews, Harris [11] reported the findings of André, who found that from a survey of 35 vehicles $52 \%$ of the vehicle journeys made were less than $3 \mathrm{~km}$ in duration. André [12] carried out extensive work investigating the driving habits and trends of vehicles used in real conditions. He found that most trips made by car owners are of a short duration in terms of both time and distance. The work investigated the driving trends of 55 vehicles and characterised $1840 \mathrm{~h}$ of vehicle running, and found that approximately one third of the trips made did not enable the engine coolant to exceed $70{ }^{\circ} \mathrm{C}$ or the engine lubricant to exceed $60{ }^{\circ} \mathrm{C}$.

In view of all these concerns, a deep assessment of the efficiency and emission behaviour in cold conditions of last generation vehicles equipped with SI (spark ignition) engines is undoubtedly essential. Therefore, an analytical-experimental study aiming at these concerns was performed by the Department of Industrial Engineering (University of Naples Federico II) and by the Istituto Motori (National Research Council, CNR-Italy) based on roller test bench measurements. Carbon monoxide and unburned hydrocarbons were measured in the exhaust emissions of two high-performance motorcycles with a displacement of $1000 \mathrm{~cm}^{3}$ in the Euro-3 type approval category. In order to allow an interesting comparison between these two vehicles, they were selected for comparable engine and after-treatment system features; besides, they are both equipped with last generation devices for increasing combustion efficiency and after-treatment systems for exhaust emissions. Therefore, the two vehicles under investigation represent a sample of the newly sold motorcycles in Europe that in recent years are also being utilised in urban contexts in industrialised countries, so playing an increasing role in urban mobility. The central aim of this study is to develop a deep understanding of the SI engine performance and emissive behaviour during the cold-start phase by means of a calculation procedure that evaluates the cold emissions of carbon monoxide and unburned hydrocarbon as a time-dependent function. This methodology was applied on the exhaust cold emissions of the two vehicles and for the examined pollutants; processing measured data allowed us to calculate the warm-up transient durations, the total exhaust emissions released during the cold-start transient and the cold-start emission factors. The emissive levels of these two motorcycles were measured in the European type approval driving cycle, namely "UDC+EUDC" (Urban Driving Cycle, Extra Urban Driving Cycle). The present investigation focused on these specific vehicles for several reasons. The two-wheeler class, in fact, is very utilised as widespread means of quotidian moving in main Asian and European cities, in which motorcycles and mopeds represent a large proportion of motorised vehicles $[13,14]$. In recent years, powered two-wheelers accounted for about 32 million vehicles in the EU-27, making up around 8\% of the urban vehicle fleet [15]. 
For example, in Italy, parking difficulties and traffic congestion affect the choice of urban transportation mobility, to the extent that the proportion of motorised two-wheelers in the whole passenger mobility fleet is nearly $25 \%[16,17]$; with around 9 million vehicles. In fact, the Italian two-wheeler vehicle fleet contributes about $28 \%$ to the whole EU-27 figures [18, 19].

Besides, for new motorcycles fitted with both a catalytic converter and electronic control of the air-fuel mixture, a major part of the exhaust emissions takes place during the warm-up phase of the trips because the engine and catalyst are much too cold. In these conditions, in fact, carbon monoxide and unburned hydrocarbon extra cold emissions represent a significant proportion of global emissions if compared with those exhausted in hot conditions [7, 20, 21]. Finally, the existing emission models for estimating emissions from road transport sector do not particularly consider the emissive behaviours of mopeds and motorcycles during the warm-up phase [22, 23]. The emissive levels and emission factors calculated in these circumstances might not be adequately descriptive of urban driving cycles since the majority of cold starts of motorised two-wheelers fall in urban contexts and thus are driven under real urban driving conditions after the start. In view of all these concerns, it is clear that a consistent assessment of the emissive behaviour in cold conditions of motorcycles (and more generally of last generation SI engines) is extremely important. In fact, the cold emission factors and all other results obtained in this study are very useful in order to better characterise the emission levels of newly sold motorcycles under real urban conditions since these vehicles in recent years have taken on an increasingly major role in private mobility with a significant environmental impact on the urban air quality of metropolitan areas. Thus, in the present paper a comparison was performed between the processing results achieved in this investigation and the emission factors obtained through an emission model for calculating emissions from the road transport sector, giving interesting results.

\section{MATERIALS AND METHODS}

\section{Experimental Details}

The chief features of the two high-performance motorcycles adopted in the experimental tests are shown in Table 1. The vehicles are fitted out with four-stroke SI engines and three-way catalytic converters for emissions abatement. The two motorcycles are also equipped with an electronic fuel injection system (in order to obtain a precise air-fuel mixing ratio) and a closed-loop exhaust after-treatment control system. Figure 1 shows one of the two vehicles on the test bench. The vehicles under investigation were selected from private owners on the basis of sales statistics relevant to the time of this study in order to represent the actual fleet distribution of in-use motorcycles. The fuel used for the test series was commercial gasoline.

Table 1. Main features of the tested motorcycles.

\begin{tabular}{ccccccc}
\hline & $\begin{array}{c}\text { Empty } \\
\text { mass } \\
{[\mathrm{kg}]}\end{array}$ & $\begin{array}{c}\text { Displac. } \\
{\left[\mathrm{cm}^{3}\right]}\end{array}$ & $\begin{array}{c}\text { Power } \\
{[\mathrm{kW}]}\end{array}$ & $\begin{array}{c}\text { Compres. } \\
\text { Ratio [-] }\end{array}$ & $\begin{array}{c}\text { Legislative } \\
\text { Category [-] }\end{array}$ & $\begin{array}{c}\text { After-treatment } \\
\text { system }\end{array}$ \\
\hline A & 185 & 982 & $\begin{array}{c}104 @ \\
10900 \mathrm{rpm}\end{array}$ & $12.2: 1$ & Euro-3 & $\begin{array}{c}\text { Three-way } \\
\text { catalytic } \\
\text { converter with } \lambda \\
\text { sensor control }\end{array}$ \\
\hline B & 189 & 999 & $\begin{array}{c}132 @ \\
12500 \mathrm{rpm}\end{array}$ & $13: 1$ & Euro-3 & \\
\hline
\end{tabular}




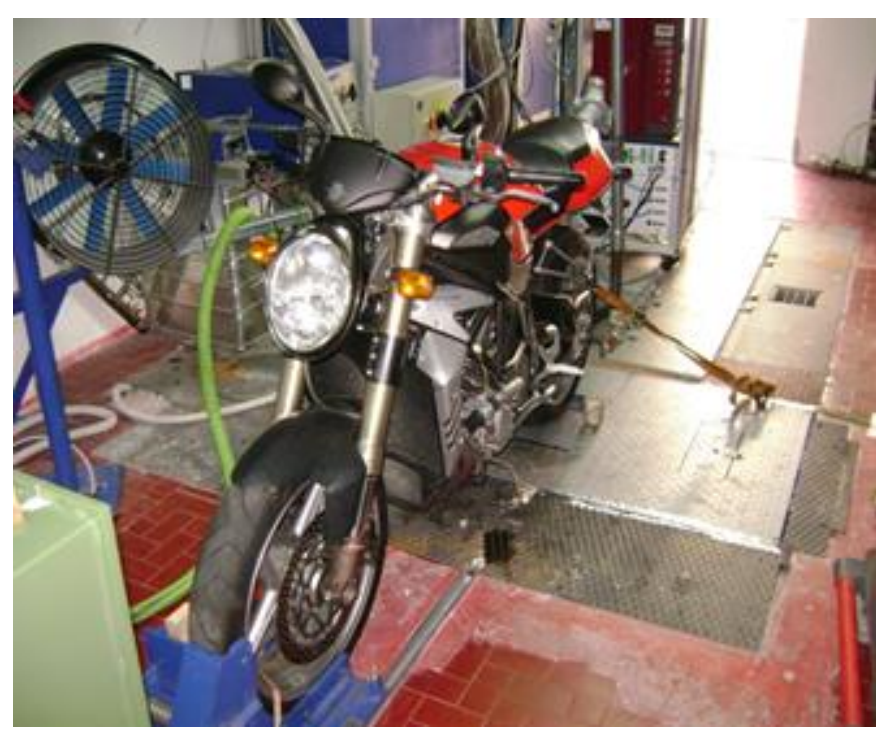

Figure 1. Vehicle A on the test bench.

Roller test bench measurements were executed in the laboratories of the Istituto Motori (National Research Council, CNR-Italy); the motorcycles under investigation were tested on a two-wheeler chassis dynamometer (AVL Zollner 2000 - single roller), which simulates road load resistance and vehicle inertia (Figure 2). The bench is arranged to reproduce the road load conditions and to measure the exhaust emissions of the two wheelers during several dynamic speed cycles. By using this chassis dynamometer, it is too possible to carry out experimental tests in constant speed mode, constant acceleration mode and constant tractive force mode. In addition, a variable speed blower, positioned in front of the vehicle, acted as the cooling wind on the road. A driver's aid displayed a speed trace of the driving cycle to follow with a tolerance of $\pm 1 \mathrm{~km} / \mathrm{h}$.

Each experimental test was performed in cold-start conditions and, before each experiment, the motorcycles were kept at a constant temperature of around $20{ }^{\circ} \mathrm{C}$ for at least $6 \mathrm{~h}$. During the experimental tests the exhaust gases of the motorcycles were diluted with filtered ambient air by a Constant Volume Sampling with Critical Flow Venturi unit. A dilution tunnel was positioned upstream of the sampling for gas analysis in order to guarantee stable flow conditions. A portion of diluted gases so obtained was sampled downstream of the dilution tunnel to continuously measure the concentrations of $\mathrm{CO}$ and $\mathrm{HC}$ in the exhaust emissions using the flame ionisation detector analyser (FID) and a nondispersive infrared analyser (NDIR) of the exhaust gas analysis system (AVL AMA 4000). The gases used in the calibration of these instruments were CO, propane, nitric oxide and carbon dioxide, which were mixed with pure nitrogen; before being tested, these analysers were calibrated daily with zero gas. All measuring instruments offered a precision of $\pm 2 \%$. The background pollutant concentrations of the indoor air were also analysed and subtracted from the test results. The only correction made to the signals is that of the delay with respect to the real speed of the vehicles. 


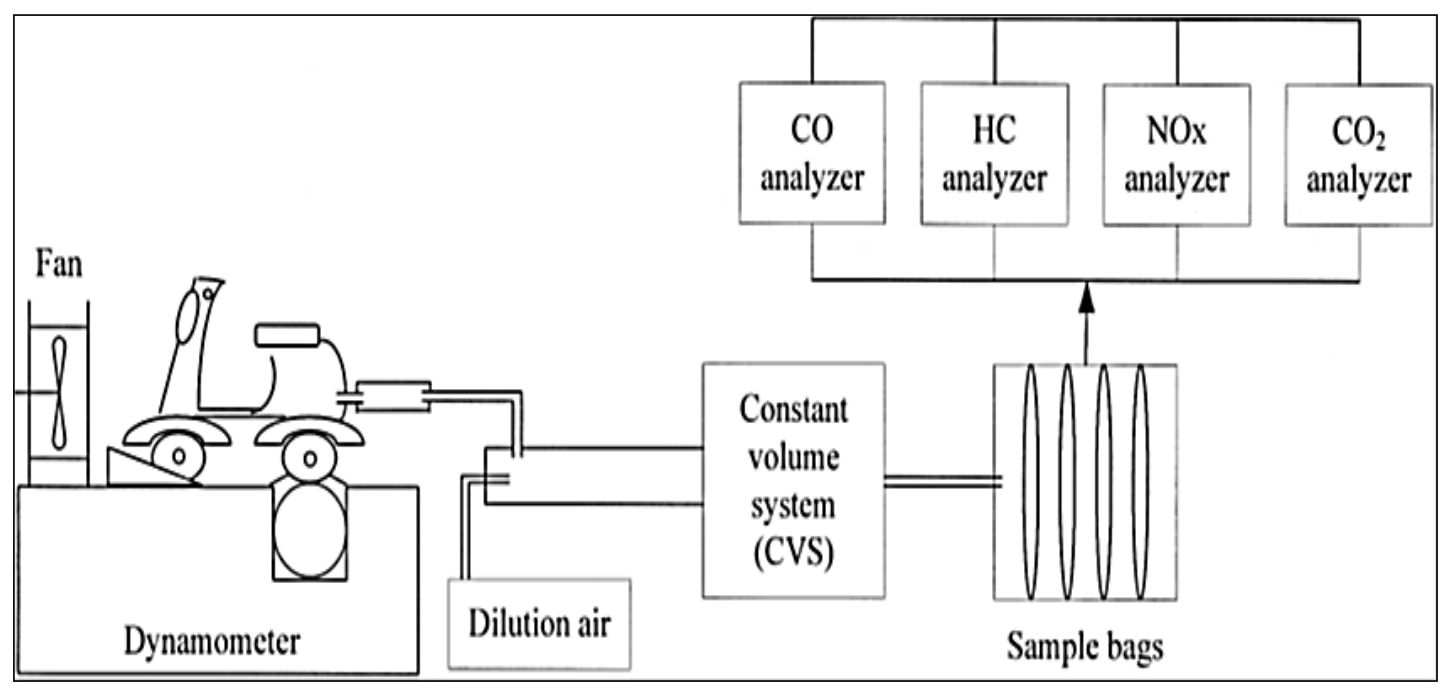

Figure 2. Illustration of the test setup.

\section{Modelling the Cold-Start Emission Performance}

The steady state performance of internal combustion engines has improved noticeably over the years, both in terms of fuel consumption and emissions quality. This can be attributed to a range of developments, including the use of common rail fuel injection, improved lubricants, more complex engine control strategies and the use of catalytic converters on most vehicles. However, the cold-start performance of vehicle engines remains difficult because the thermal efficiency of the internal combustion engine is meaningfully lower at cold-start than in hot conditions owing to sub-optimal lubricant and component temperatures. During the cold-start phase, in fact, as little as $9 \%$ of the energy in the fuel is converted to effective work, as a result of components and fluids being below their optimal temperatures $[24,25]$. The energy thermal balance during the warm-up phase in the combustion chamber of a four-cylinder $1700 \mathrm{~cm}^{3}$ spark ignition engine provided a breakdown of the 53\% of energy that is transferred as heat to the cylinder walls. The energy transferred to the cylinder walls causes the coolant, the metallic structure (including the block and crankshaft) and the lubricant to warm up. However, what was indicated is that $52 \%$ of this transferred heat energy is not found to warm up any of the ancillary circuits (such as the lubricant or coolant), but is instead lost directly to the environment (unused heat). It was also noted that only $4 \%$ of the heat from combustion will be found to actually warm up the lubricant [24]. Similarly, the theoretical modelling work of Samhaber, Wimmer [26] detailed the energy balance of the heat sink of a diesel engine. In this work, it was found that $60 \%$ of the energy was used to heat the structural parts, with approximately $20 \%$ being absorbed by the coolant and $10 \%$ by the lubricant. Therefore, rates of emission and fuel consumption are higher during the warmup phase than during thermally stable operation, mostly in the case of petrol-engine vehicles. There are a number of specific reasons for this, including in particular the following:

\section{Partial Combustion}

In the cold-start phase, engine components are not yet at the operation temperature. In particular, the fuel can condense on the cool walls of the inlet manifold and the cylinder. It is therefore necessary to increase the supply of fuel to support combustion and 
drivability. The engine then works in conditions of rich combustion and, consequently, concentrations of $\mathrm{CO}$ and unburned hydrocarbons in the exhaust increase [3, 27].

\section{Catalyst Inefficiency}

For petrol engine vehicles equipped with a three-way catalyst, the performance of the catalyst is reduced during the cold-start transient. The oxidation-reduction reactions occurring in the three-way catalyst reach the maximum conversion efficiency ( $99 \%$ for $\mathrm{CO}$ and $95 \%$ for $\mathrm{HC}$ ) when combustion evolves at stoichiometric conditions and when the light-off temperature of the catalyst is around $300{ }^{\circ} \mathrm{C}$ (below this temperature, removal of pollutants is minimal). These conditions are not guaranteed during the warm-up phase, so reducing the conversion efficiency of the catalyst [27].

\section{Increased Friction}

During the warm-up phase, the temperature of the lubricants is lower than optimal (100$110{ }^{\circ} \mathrm{C}$ ) and thus their viscosity is higher than under normal operation conditions [28]. This entails higher friction between moving components and hence a lower efficiency of the engine [24]. Will and Boretti [25] estimated that frictional losses in the engine during the early stages of warm-up (when the engine is in the range of $20{ }^{\circ} \mathrm{C}$ ) can be up to 2.5 times higher than those detected when the lubricant is fully warm. With these premises, therefore, it is clear that during the engine warm-up phase there are effectively three thermal masses interacting with each other, namely the main engine block, the lubricant and the coolant. Of the three, the coolant is the fastest to respond owing to its temperature being closely coupled to that of the combustion gases [29, 30]. In contrast, the lubricant temperature and block temperature are generally much slower to respond owing to the block having a large thermal inertia and the lubricant being much less closely coupled to the combustion process $[31,32]$. During the early phases of warm-up when the cylinder walls are cold, most of the energy from combustion is transferred to the walls owing to the high temperature differential between them and the combustion gases [33, 34]. In previous publications [20,35], a methodology was presented to describe the examined cold-start phase, and now this procedure is concisely summarised. Cold-start emissions can be described by a cold instantaneous emission factor $f_{\text {cold }}(t)$, expressed as mass per time unit; in order to characterise the shape of this time-dependence function the following assumptions were considered.

This cold emission $f_{\text {cold }}(t)$ with time during the warm-up phase of SI engines can be split up into three different phases for both carbon monoxide and unburned hydrocarbons. During the first instants of warm-up, when the cylinder walls are cold, most of the energy from combustion is transferred to the walls owing to the high temperature differential between them and the combustion gases; therefore the "first phase" of the cold transient is characterised by the highest cold-start emissions owing to the greatest enrichment of the fuel-air ratio and to the lower temperatures of the engine, lubricant and catalytic converter. During the "second phase" of the cold-start transient, emissions decline owing to the gradual increase of the catalyst and engine temperatures and the lower enrichments of the air-fuel mixture ratio. The last rather stable phase ("third phase") is characterised by the lowest cold emissions because the operating temperatures are achieved and the air-fuel mixture values are very near to the stoichiometric ratio. Starting from these assumptions, therefore, extra emissions during operation of the coldstart engine can be represented by a cold emission factor $f_{\text {cold }}(t)$, represented by Equation (1), expressed through two parameters: " $T_{\text {reg }}$ ", which is the cold transient duration, and " $f 0$ ", which is the value of this analytical function for the instant $t=0$ (explicitly: $f_{0}=f_{\text {cold }}(t$ 
$=0)$ ). For the calculation of these two parameters, experimental data on the emission levels detected during the transient phase must be identified, as will be explained in the next section. However, on the basis of the previous assumptions, it is evident that this function satisfies two precise boundary conditions; this function, in fact, is always decreasing during the transient duration and the fist derivative is equal to zero at the end of the cold transient duration (namely $T_{r e g}$ ).

On the other hand, the analytical function of the cold cumulative extra emissions is calculated by integration of the function $f_{\text {cold }}(t)$ (Equation (1)), so obtaining Eq. (2).

$$
\begin{gathered}
f_{\text {cold }}(t)=f_{0}\left(e^{\frac{t}{T_{\text {reg }}}}-e \cdot \frac{t}{T_{\text {reg }}}\right)[\mathrm{g} / \mathrm{s}] \\
E_{\text {cold }}(t)=\int_{0}^{t} f_{\text {cold }}(t) d t=f_{0}\left(T_{\text {reg }} \cdot e^{\frac{t}{T_{\text {reg }}}}-\frac{e \cdot t^{2}}{2 T_{\text {reg }}}-T_{\text {reg }}\right)[\mathrm{g}]
\end{gathered}
$$

\section{RESULTS AND DISCUSSION}

Both vehicles under investigation were equipped with electronic fuel injection systems, and the control of fuel feeding and increasing catalyst efficiency are also ensured during the transient phase; the on-board central unit (ECU) controls the fuel injection strategy with feedback signals that come from the oxygen sensor located in the exhaust tube. In these specific operating conditions, the cold emissive behaviour of these motorcycles was analysed under the original strategy of the fuel injection system. Information on the cold transient phase of the examined vehicles was obtained by applying the calculation procedure (summarised above) on the exhaust emissions measured during the UDC driving cycle. According to regulations of Stage 3 (Euro-3) of Directive 97/24/EC, more stringent emission limits entered into force for the two-wheelers category and substantial improvements were introduced with reference to normalised cycles: while until Euro-2 phase only a hot urban phase was considered, starting with Euro-3 phase, the Type Approval test cycle was replaced by a combination of "UDC" and "EUDC" phases for vehicles with an engine displacement $>150 \mathrm{~cm}^{3}$, and a more comprehensive assessment of the emissive behaviour was mandatory, including cold start.

By processing the experimental exhaust emissions measured during the cold start of the "UDC" driving cycle, the experimental curves of total cumulative emissions were obtained as a function of the time for $\mathrm{CO}$ and $\mathrm{HC}$; the contribution of hot emissions to these cumulative curves can be fitted with a linear regression that is characterised by high correlation coefficients. The duration $T_{\text {reg }}$ of the cold transient is calculated as the instant in which the curve of the cumulative emissions diverges from the linear regression. In Figure 3, HC total cumulative emissions were measured on motorcycle $\mathrm{B}$ during the "UDC" driving cycle (similar results were obtained for CO emissions). Further, in order to set the parameter $f_{0}$, the experimental and analytical curves of the "cold" cumulative extra emission were achieved: the experimental curves were obtained through the "total" cumulative curves of emissions (already defined and shown in Figure 3) by subtracting the hot phase linear regression during the transient duration. The analytical curves, on the other hand, were calculated as in Equation (2). In Figure 4, parameter $f_{0}$ for $\mathrm{HC}$ is chosen so that the analytical function fits the experimental curve. 


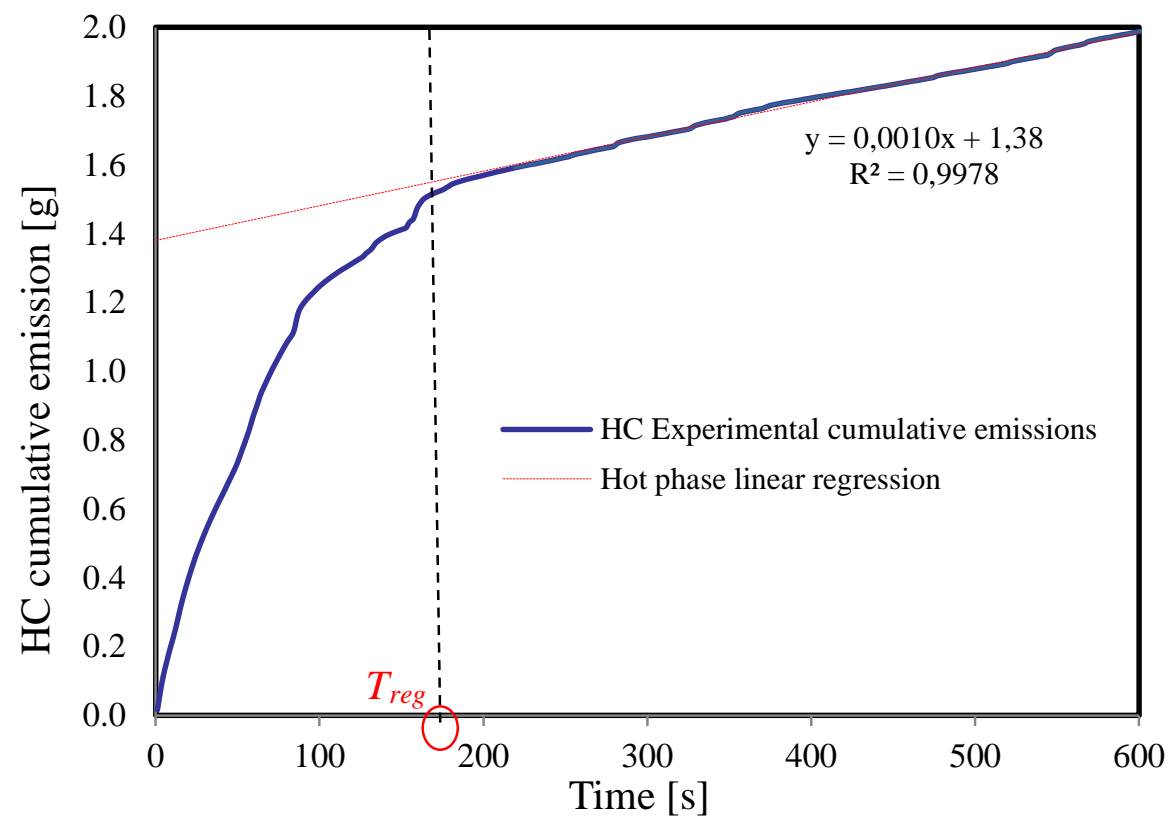

Figure 3. HC experimental cumulative emissions measured on motorcycle B during the "UDC" driving cycle.

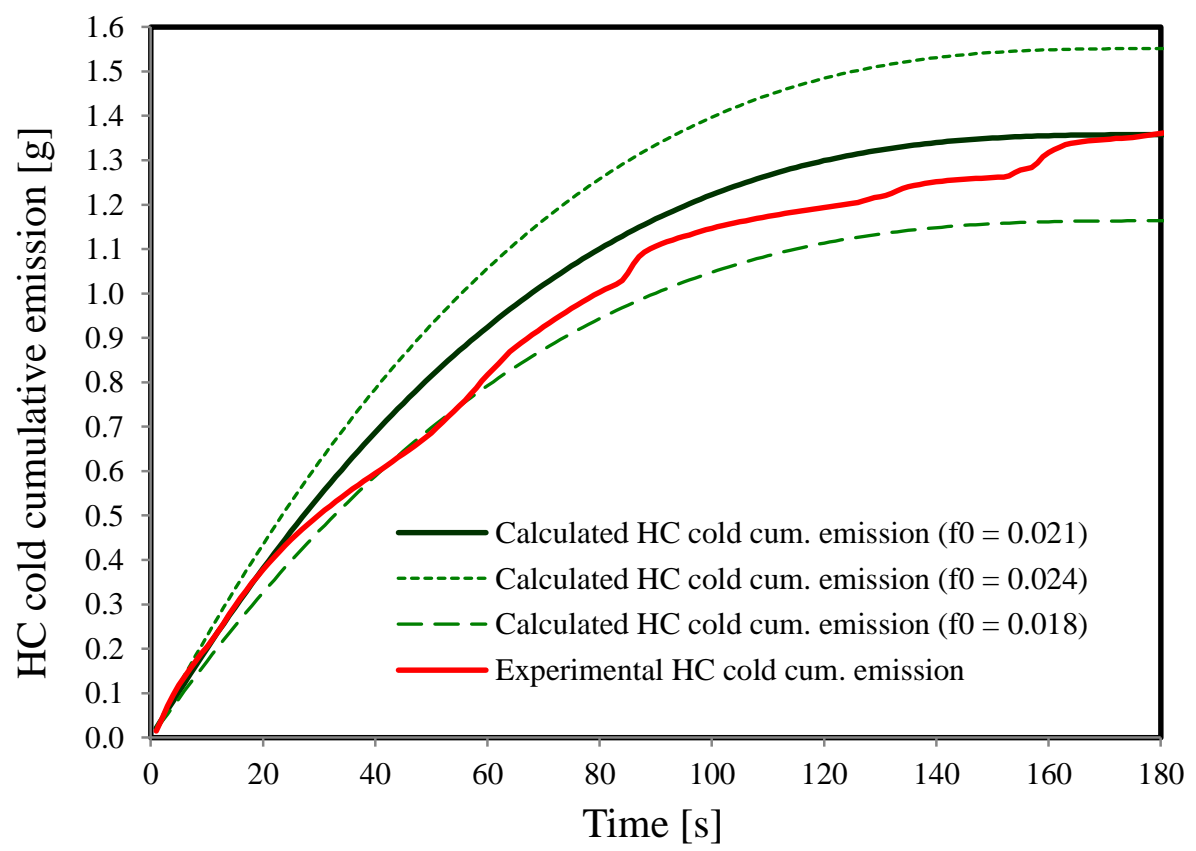

Figure 4. Experimental and calculated HC cold cumulative extra emissions for the motorcycle B during UDC driving cycle

By using the values of $T_{\text {reg }}$ and $f_{0}$ so obtained, $\mathrm{CO}$ and $\mathrm{HC}$ cold instantaneous emissions $f_{\text {cold }}(t)$ with time, corresponding to both motorcycles, were calculated using Equation (1) and are shown in Figure 5, while in Table 2 the total cold-start emissions of these pollutants were calculated by applying Equation (2) for $t=T_{r e g}$, so obtaining $E_{c}$. By analysing Figure 5 for $\mathrm{CO}$ and $\mathrm{HC}$, the second phase of the cold transient is clearly visible, which is characterised by a marked drop of the cold emissions owing to the gradual rise 
of temperatures and for the lower enrichments of the air-fuel mixture. The last phase is also evident, characterised by the minimum cold emissions, because the normal operating temperatures of the catalyst and engine are achieved and the air-fuel mixture is very close to the stoichiometric ratio. It is evident that the cold transient duration $T_{\text {reg }}$ can also be derived by analysing the time-dependent functions represented in Figure 5, because the pertinent equations are equal to zero for $t=T_{\text {reg }}$; the cold transient durations $T_{\text {reg }}$, calculated according to this calculation procedure, are equal (on average) to about $150 \mathrm{~s}$ for $\mathrm{CO}$ and $160 \mathrm{~s}$ for $\mathrm{HC}$.

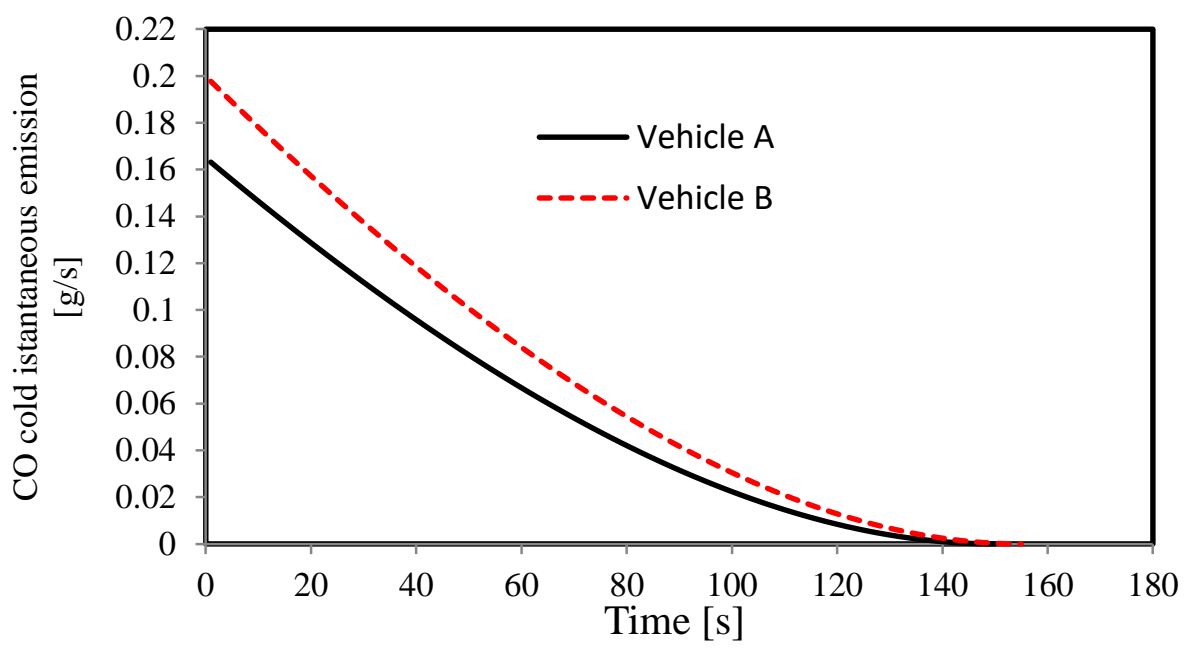

(a)

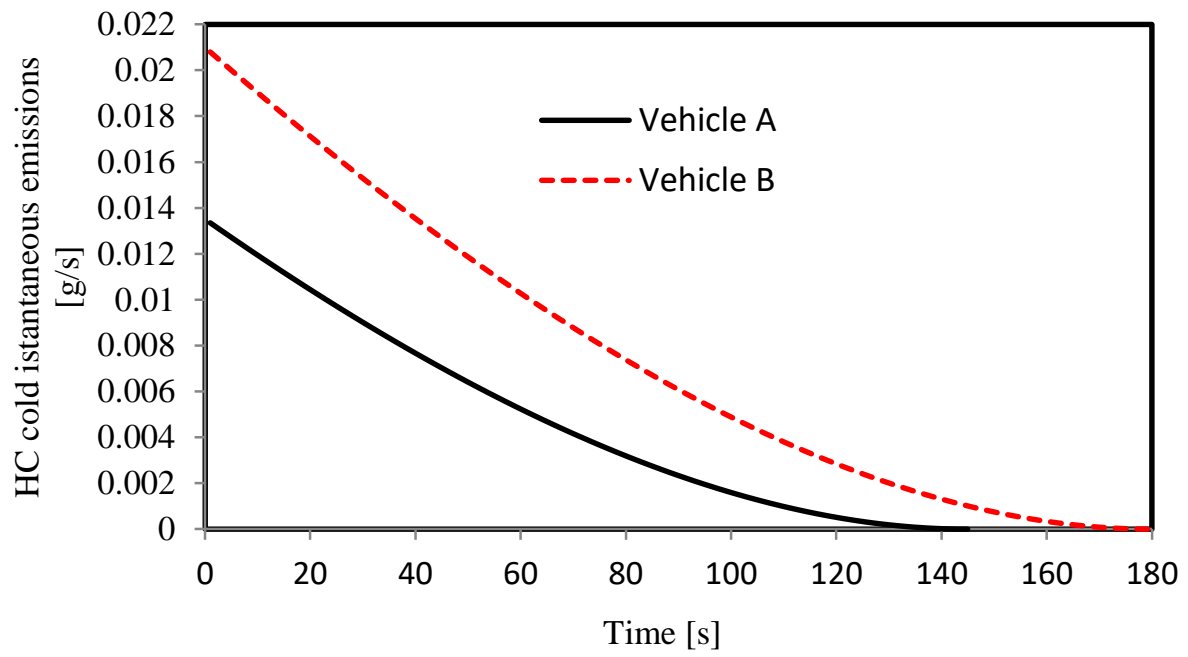

(b)

Figure 5. Calculated $\mathrm{CO}$ and $\mathrm{HC}$ cold instantaneous emissions versus time in the UDC driving cycle for the two motorcycles

By analysing the cold/hot emission ratios for the vehicles and pollutants shown in Table 2, it is evident that for the motorcycles under investigation a considerable difference exits between emissions calculated during the cold-start phase and the emissions detected during the hot phase as a result of catalytic technology and improved SI engines adopted on these motorcycles. In particular, the reason may be attributed to numerous factors. Primarily, during the warm-up transient phase the SI engines need a rich air-fuel mixture 
(outside the optimum stoichiometric range) in order to compensate for the gasoline that does not contribute to the combustion process since the fuel condenses on the cold inside walls of the engine and for the fuel that has not still evaporated [3, 27]. Formation of carbon monoxide, in fact, depends mostly on the air-fuel mixture ratio: with regard to the two motorcycles under investigation, during the warm-up phase of the engine, mixture enrichment increases $\mathrm{CO}$ emission levels if compared with the exhaust emissions detected for stable engine operations $[20,35]$.

Table 2. Cold transient information of carbon monoxide and unburned hydrocarbons obtained for the two tested vehicles in the UDC driving cycle.

\begin{tabular}{|c|c|c|c|c|c|c|}
\hline & & $\begin{array}{c}\text { Transient } \\
\text { duration } T_{\text {reg }}[\mathrm{s}]\end{array}$ & $\begin{array}{l}\text { Cold-start } \\
\text { emission } E_{C} \\
\text { [g] }\end{array}$ & $\begin{array}{c}\text { Cold } \\
\text { emission } \\
\text { factor }[\mathrm{g} / \mathrm{km}]\end{array}$ & $\begin{array}{l}\text { Hot emission } \\
\text { factor }[\mathrm{g} / \mathrm{km}]\end{array}$ & $\begin{array}{c}\text { Cold/Hot } \\
\text { emission } \\
\text { quotient } \\
{[-]}\end{array}$ \\
\hline & $\mathrm{A}$ & 150 & 9.32 & 14.27 & 0.61 & 20.71 \\
\hline \multirow[b]{2}{*}{$\mathrm{CO}$} & B & 155 & 11.12 & 15.47 & 1.35 & 10.25 \\
\hline & $\begin{array}{l}\text { Average } \\
\text { values }\end{array}$ & 152 & 10.22 & 14.87 & 0.98 & 15.48 \\
\hline \multirow{3}{*}{$\mathrm{HC}$} & A & 145 & 0.72 & 1.23 & 0.10 & 10.13 \\
\hline & $\mathrm{B}$ & 180 & 1.38 & 1.41 & 0.22 & 7.59 \\
\hline & $\begin{array}{l}\text { Average } \\
\text { values }\end{array}$ & 162 & 1.05 & 1.32 & 0.16 & 8.86 \\
\hline
\end{tabular}

In addition, at the lowest temperatures of ambient air, the cold engine during the cold phase hinders gasoline vaporisation, thus increasing the formation of unburned fuel and leading to increased unburned hydrocarbon emissions as a result of there being too much fuel present to achieve complete combustion. Furthermore, the fuel returning from forming a surface film on the combustion chamber surface is particularly poorly mixed and therefore poorly burnt [35]. Lastly, during the initial instants of the warm-up phase, the efficiency of the catalytic converter proves insufficient owing to rich levels of airfuel mixture and to temperatures of exhaust emissions at the catalyst inlet much lower than the light-off temperature of the catalytic converter. Under these particular functioning conditions, the gasoline that has not combusted, or just partially, flows through the catalytic converter untreated in the form of CO and HC. During the cold phase, therefore, the engine and catalyst are not at their optimal operating conditions: assuming that it is the equivalent rich air-fuel ratio with the catalytic converter that misses achieving the light-off temperature, the examined vehicles have produced higher cold extra emissions.

\section{Comparisons with Emission Models}

The results and experimental data obtained in this research allow us to develop a comparison with an emission model for calculating emissions from road traffic, namely ARTEMIS. The ARTEMIS project (Assessment and Reliability of Transport Emission Models and Inventory Systems) generated an emission model for all transport means and its objective is to offer reliable emission estimates at the regional, national and international levels. This project contains 13 work packages, and of these Elst, Gense [23] focuses on emissions of powered two-wheeler vehicles. The ARTEMIS WP500 project 
is centred on many online and bag emission results both from numerous experimental studies and international measurement programmes developed during the last years. Consequently, the focal target of the ARTEMIS WP500 project was to improve the typical emissions database for $\mathrm{CO}, \mathrm{HC}$ and $\mathrm{NO}_{\mathrm{X}}$, available for both old and last generation motorised two-wheeler vehicles, that will be the source for the emission models of this vehicle category. Cold-start additional emissions for regulated pollutants in mass units (for Euro-3 motorcycles with swept volume between 750 and $1000 \mathrm{~cm}^{3}$ ) resulting from the ARTEMIS WP500 measurement programme are presented in Table 3; these values are given by the difference between emissions measured in the first two UDC sub-cycles required for complete warming-up of the engine and emissions measured during the subsequent two sub-cycles with a warmed engine. On the other hand, experimental values of the cold-start extra emissions detected on the tested motorcycles are displayed in Table 2. It is noteworthy in this table that cold-start extra emissions measured for the two motorcycles are lower than the ARTEMIS WP500 values, as the tested vehicles are fitted with very efficient electronic fuel injection systems [20], so providing improved fuel feeding control and increasing the efficiency of the catalytic converter during the cold transient compared to the emission results of motorcycle sample considered in the ARTEMIS WP500 measurement programme.

Table 3. Cold-start extra emissions in the UDC driving cycle: comparison of ARTEMIS WP500 measurement programme and measured values on the tested motorcycles.

\begin{tabular}{|c|c|c|}
\hline Vehicle Class & & \\
\hline $\begin{array}{l}\text { Motorcycles - Euro-3 - Engine capacity class }>750 \\
\mathrm{~cm}^{3}\end{array}$ & {$[\mathrm{~g}]$} & {$[\mathrm{g}]$} \\
\hline $\begin{array}{l}\text { Values of ARTEMIS WP500 measurement } \\
\text { programme }\end{array}$ & 15.51 & 2.00 \\
\hline Experimental values obtained on the tested vehicles & 10.22 & 1.05 \\
\hline
\end{tabular}

\section{CONCLUSIONS}

In this study, a numerical-experimental procedure was optimised and applied to assess the cold transient emission behaviour of new-generation SI engines. For this purpose, two last generation motorcycles were operated on a chassis dynamometer for exhaust emission measurements. The main results can be summarised as follows:

a) $\mathrm{CO}$ and $\mathrm{HC}$ formation in the engines of these motorcycles depend mostly on the air-fuel mixture ratio: during the warm-up phase of the engine, mixture enrichment increases $\mathrm{CO}$ emission levels if compared with the exhaust emissions detected for stable engine operations. In addition, at the lowest temperatures of ambient air, the cold engine during the cold phase hinders gasoline vaporisation, thus increasing the formation of unburned fuel and leading to increased unburned hydrocarbon emissions.

b) Regarding $\mathrm{HC}$, the experimental values of cold-start extra emissions are $0.7 \mathrm{~g}$ and $1.4 \mathrm{~g}$, and the warm-up transient durations ranged between $145 \mathrm{~s}$ and $180 \mathrm{~s}$. Regarding CO, cold-start extra emissions are $9.3 \mathrm{~g}$ and $11.1 \mathrm{~g}$, and the coldphase durations were around $150 \mathrm{~s}$.

c) Decreasing cold-start enrichments for the tested vehicles in comparison with the results of the ARTEMIS WP500 emission model may be the result of internal 
engine optimisation and more accurate air-fuel mixture control of electronic fuel injection systems adopted on the tested motorcycles.

For these motorcycles (and more generally for similar vehicles equipped with last generation SI engines), the temperature of the catalytic converter and air-fuel mixture fraction therefore define the functioning of the catalyst and consequently also the net exhaust emissions during the cold transient. For this reason, improving the combustion process, the fuel injection strategies and the exhaust after-treatment systems are necessary in order to decrease the $\mathrm{CO}$ and $\mathrm{HC}$ cold emissions of these vehicles. Furthermore, the statistical processing results obtained in this study are very useful in order to improve the database of emission models commonly used for estimating emissions from the road transport sector. They can then be used to evaluate the environmental impact of last generation motorcycles under real driving behaviours.

\section{ACKNOWLEDGEMENTS}

The authors of this paper thank the colleagues of Istituto Motori of the National Research Council (CNR-Italy) for the assistance in performing experimental tests. There were not any institutional contributions or sources of funding for this study

\section{REFERENCES}

[1] Iodice P, Senatore A. Analytical-experimental analysis of last generation medium-size motorcycles emission behaviour under real urban conditions. International Journal of Automotive and Mechanical Engineering. 2015;12:301832.

[2] Abas M, Said MM, Abidin SZ, Zahari I. Simulation of fuel economy for malaysian urban driving. International Journal of Automotive and Mechanical Engineering. 2015;11:2306-16.

[3] Roberts A, Brooks R, Shipway P. Internal combustion engine cold-start efficiency: A review of the problem, causes and potential solutions. Energy Conversion and Management. 2014;82:327-50.

[4] Ramasamy D, Aik Soon K, Walker-Gitano Briggs H, Zainal ZA. Variation of airflow pattern through dissimilar valve lift in a spark ignition engine. Journal of the Chinese Institute of Engineers, Transactions of the Chinese Institute of Engineers,Series A/Chung-kuo Kung Ch'eng Hsuch K'an. 2013;36:1083-96.

[5] Ramasamy D, Bakar RA, Kadirgama K. Mass fraction burn comparison of compressed natural gas and gasoline. Applied Mechanics and Materials. 2014;442-6.

[6] Iodice P, Senatore A. Influence of ethanol-gasoline blended fuels on cold start emissions of a four-stroke motorcycle. Methodology and results. SAE Technical Paper NO. 2013-24-0117; 2013.

[7] Ramasamy D, Kadirgama K, Rahman MM, Zainal ZA. Analysis of compressed natural gas burn rate and flame propagation on a sub-compact vehicle engine. International Journal of Automotive and Mechanical Engineering. 2015;11:240516.

[8] Ramasamy D, Zainal ZA, Kadirgama K, Walker-Gitano Briggs H. Effect of dissimilar valve lift on a bi-fuel CNG engine operation. Energy. 2016;112:50919. 
[9] Goettler HJ, Vidger LJ, Majkrzak DS. The effect of exhaust-to-coolant heat transfer on warm-up time and fuel consumption of two automobile engines. SAE Technical Paper NO. 860363; 1986.

[10] Jarrier L, Champoussin J, Yu R, Gentile D. Warm-up of a di diesel engine: Experiment and modeling. SAE Technical Paper No. 2000-01-0299; 2000.

[11] Andrews G, Harris J, Ounzain A. SI engine warm-up: water and lubricating oil temperature influences. SAE Technical Paper; 1989.

[12] André M. In actual use car testing: 70,000 kilometers and 10,000 trips by 55 French cars under real conditions. SAE Technical Paper NO. 910039; 1991.

[13] Vasic A-M, Weilenmann M. Comparison of real-world emissions from twowheelers and passenger cars. Environmental science \& technology. 2006;40:14954.

[14] Hamada KI, Rahman M. An experimental study for performance and emissions of a small four-stroke SI engine for modern motorcycle. International Journal of Automotive and Mechanical Engineering. 2014;10:1852-65.

[15] Energy E. Transport in Figures'-Statistical pocketbook 2005. European Commission, DG TREN in co-operation with Eurostat. 2006.

[16] Iodice P, Senatore A. Appraisal of pollutant emissions and air quality state in a critical Italian region: methods and results. Environmental Progress \& Sustainable Energy. 2015;34:1497-505.

[17] Iodice P, Senatore A. Environmental assessment of a wide area under surveillance with different air pollution sources. Engineering Letters. 2015;23:156-62.

[18] Prati MV, Zamboni G, Costagliola MA, Meccariello G, Carraro C, Capobianco M. Influence of driving cycles on Euro 3 scooter emissions and fuel consumption. Energy Conversion and Management. 2011;52:3327-36.

[19] Iodice P, Senatore A. Road transport emission inventory in a regional area by using experimental two-wheelers emission factors. World Congress on Engineering. 2013;2078-0958.

[20] Iodice P, Senatore A. Exhaust emissions of new high-performance motorcycles in hot and cold conditions. International Journal of Environmental Science and Technology. 2015;12:3133-44.

[21] Ramasamy D, Bakar RA, Rahim MF, Noor MM. Comparative evaluation of a two stroke compressed natural gas mixer design using simulation and experimental techniques. Proceedings of the 4th IASTED Asian Conference on Power and Energy Systems, 2008;359-62.

[22] Kouridis C, Ntziachristos L, Samaras Z. COPERT III: Computer Programme to Calculate Emissions from Road Transport: User Manual (version 2.1): European Environment Agency; 2000.

[23] Elst D, Gense N, Vermeulen R, Steven H. Artemis WP500 Final report ARTEMIS project deliverable D 5. 2006.

[24] Trapy J, Damiral P. An investigation of lubricating system warm-up for the improvement of cold start efficiency and emissions of SI automotive engines. SAE Technical Paper NO. 902089; 1990.

[25] Will F, Boretti A. A new method to warm up lubricating oil to improve the fuel efficiency during cold start. SAE international journal of engines. 2011;4:175-87.

[26] Samhaber C, Wimmer A, Loibner E. Modeling of engine warm-up with integration of vehicle and engine cycle simulation. SAE Technical Paper NO. 2001-01-1697; 2001. 
[27] Heywood J. Internal combustion engine fundamentals: McGraw-Hill Education; 1988.

[28] Kamil M, Rahman M, Bakar RA. An integrated model for predicting engine friction losses in internal combustion engines. International Journal of Automotive and Mechanical Engineering. 2014;9:1695-708.

[29] Will F. Fuel conservation and emission reduction through novel waste heat recovery for internal combustion engines. Fuel. 2012;102:247-55.

[30] Bent E, Shayler P, La Rocca A, Rouaud C. The effectiveness of stop-start and thermal management measures to improve fuel economy. Vehicle thermal Management Systems Conference Proceedings, Coventry Technocentre, UK; 2013. p. 27.

[31] Li H, Andrews GE, Savvidis D, Daham B, Ropkins K, Bell M, et al. Study of thermal characteristics and emissions during cold start using an on-board measuring method for modern SI car real world urban driving. SAE International Journal of Engines. 2008;1:804-19.

[32] Kunze K, Wolff S, Lade I, Tonhauser J. A systematic analysis of co2-reduction by an optimized heat supply during vehicle warm-up. SAE Technical Paper; 2006.

[33] Beccari A, Beccari S, Pipitone E. An analytical approach for the evaluation of the optimal combustion phase in spark ignition engines. Journal of Engineering for Gas Turbines and Power. 2010;132:032802.

[34] Iodice P, Senatore A, Langella G, Amoresano A. Effect of ethanol-gasoline blends on $\mathrm{CO}$ and $\mathrm{HC}$ emissions in last generation SI engines within the cold-start transient: An experimental investigation. Applied Energy. 2016;179:182-90.

[35] Shayler P, Christian S, Ma T. A model for the investigation of temperature, heat flow and friction characteristics during engine warm-up. SAE Technical Paper No. 931153; 1993. 